\title{
Jogando com a Verdade. Uma Leitura de Foucault
}

JOEL BIRMAN

\section{RESUMO}

Neste artigo propõe-se a leitura do pensamento de Foucault a partir da categoria jogo de verdade, enunciada no final do seu percurso teórico. Para tal procura-se estabelecer as proximidades e diferenças entre esta categoria e a de jogos de linguagem, enunciada por Wittgenstein em "Investigações filosóficas". Desta maneira Foucault procurou realizar sua crítica à tradição metafísica.

Palavras-chave: Jogos de verdade; jogos de linguagem; arqueologia; genealogia. 


\section{Arquivos}

Não obstante seu desaparecimento relativamente precoce, antes dos sessenta anos de idade, Foucault nos legou uma obra imensa nas suas três décadas de produção intelectual quase incessante. "Quase" porque houve uma interrupção significativa (oito anos) na publicação de seus livros sobre a História da sexualidade. As edições do primeiro volume, em 1976 ( $L a$ volonté de savoir) e dos dois seguintes datam de 1984 (L'usage des plaisirs e Le souci de soi), pouco antes de sua morte prematura.

O intervalo de relativo silêncio foi bastante rico de reflexões teóricas, certamente, não passando em brancas nuvens. Durante esse período, Foucault inventou novos conceitos e forjou um outro recomeço para o seu projeto filosófico, denominado de estética e de estilística da existência (Foucault, La volonté de savoir, 1976), apresentado em inúmeras conferências e cursos, realizados na França e no estrangeiro.

Antes disso, no entanto, a produção teórica de Foucault foi marcada não apenas pela constância notável, considerando-se os desafios teóricos que se propunha a realizar em pequenos espaços de tempo, mas também pela ousadia das hipóteses que formulou e desenvolveu ao longo de suas publicações. O que trazia a público era sempre polêmico, seja pela originalidade de seu discurso teórico, seja pelas reviravoltas surpreendentes que sempre provocava no campo das concepções estabelecidas. Por isso mesmo, criou modas intelectuais a partir do que enunciava e de como as formulava, inscrevendo-se no centro da cena intelectual durante toda a sua vida.

Ao lado disso, foi um escritor de alto coturno, dotado de uma prosa na qual conjugava o rigor dos enunciados filosóficos com a erudição do pesquisador de arquivos esquecidos na Biblioteca Nacional de Paris, além de ser possuidor de um notável talento literário, por todos reconhecido. A beleza de suas páginas escritas era quase inigualável no seu tempo e ainda hoje o é. Foi indiscutivelmente um inovador brilhante, que nos apresentou uma outra maneira de conceber o que é a filosofia e o seu lugar no mundo de hoje. A leitura de sua obra nos revela isso a todo momento, sendo sempre instigante para provocar nossa capacidade de pensar e dizer, tal sua riqueza, fecundidade e viço.

Como se ordena a obra em questão? Constitui-se de três partes bem delimitadas, no que se refere à ordem discursiva e os arquivos que estão em pauta, mas que se relacionam entre si de maneira evidente. Existem, inici- 
almente, diversos livros sobre temas bem específicos, oriundos de pesquisas pontuais e bem definidas. Estas se centram em diferentes problemáticas, sempre originais para a investigação filosófica de então, tais como: a loucura $^{2}$ a medicina (Foucault, Naissance de la clinique, 1963), o discurso ${ }^{3}$, o saber $^{4}$, o poder (Foucault, 1974) e a sexualidade ${ }^{5}$.

Ao lado disso, Foucault produziu um número gigantesco de artigos e ensaios, publicados em revistas e como capítulos de livros, que foram reunidos, após a sua morte, em conjunto com suas conferências, numa obra intitulada Ditos e escritos (Foucault, 1994). Finalmente, as transcrições de seus cursos, no Collège de France, têm sido publicadas progressivamente, após sua morte, contando já com alguns volumes ${ }^{6}$.

Parece clara a relação existente entre os diversos arquivos discursivos. As obras publicadas como livros, resultantes de pesquisas sistemáticas e bastante concisas, eram o ponto de chegada triunfal do laboratório de idéias que Foucault cultivava de maneira experimental nos seus artigos, ensaios, conferências e cursos. Nestes, Foucault era muito mais ousado, na sua liberdade de enunciar hipóteses e possibilidades teóricas outras de interpretação, do que nos seus livros, na medida em que aqui a exigência de demonstração exaustiva se fazia de maneira bem mais patente. $\mathrm{O}$ rigor conceitual se impôs como um imperativo, com limites relativos para a liberdade enunciativa do pensamento, que se faz sempre presente no ensaio e na intervenção oral. Porém, a circularidade existente entre os diferentes arquivos é bastante óbvia, tanto pela natureza dos temas quanto pelas interpretações que orientam a leitura dessas problemáticas, de maneira que não vale mais a pena insistir sobre isso.

Considerando então os diversos arquivos discursivos como materialidades enunciativas que são do pensamento teórico de Foucault, a questão que se impõe agora é como formular uma proposta inicial de leitura que seja capaz de articular, na sua diversidade e diferença, a perspectiva filosófica de Foucault? Como puxar o fio que seja capaz de desenovelar o que existe de singularidade nessa brilhante produção teórica? Qual seria a marca desse fio para que se inscreva efetivamente no tecido da obra em pauta, de forma a não ser uma violentação desta?

Vamos começar esta incursão formulando uma hipótese inicial de interpretação da obra de Foucault, que nos parece ser parte integrante dela e que nos acompanhará ao longo deste ensaio. Existem também outras propostas de leitura da obra, evidentemente, que serão evocadas de passagem. No entanto, a hipótese inicial servirá de fio condutor para ordenar esta exposição. 


\section{Atualidade e Finitude}

Em 1984, já no final de seu percurso, Foucault publicou um ensaio fundamental para a compreensão de seu projeto filosófico. Sob o título "O que é o Iluminismo" (Foucault, 'Qu'est-ce que les Lumières?', 1984), Foucault comentou o célebre escrito de Kant sobre a filosofia iluminista e sobre o horizonte que teria sido entreaberto pela modernidade. Kant articulava o ideário teórico do Iluminismo com a conquista da maioridade da razão, que foi empreendida vigorosamente pela tradição ocidental no século XVIII. Para Foucault, em contrapartida, caberia interpretar essa proposição de Kant no sentido de que a filosofia deveria se voltar para a atualidade e o tempo presente, estando aqui o signo mais eloqüente daquilo que Kant nomeou como maioridade da razão.

$\mathrm{O}$ que quer dizer isso, afinal? O que pretende nos sugerir Foucault com essa formulação inesperada? Com o enunciado do imperativo, ético e político, de que a filosofia deveria se voltar para a atualidade, Foucault nos propõe que seja superada a oposição entre o passado e o presente, no sentido de se julgar sempre o presente a partir dos cânones do passado, como já se fazia desde o Renascimento. Vale dizer, a maioridade da razão, formulada por Kant, implicava superação da famosa querela dos antigos e dos modernos, iniciada no final do século XVII e que perdurou longamente, ainda no século XVIII, com vistas a que se pensasse e se escrevesse sempre a partir de cânones definidos pelo presente. Seria sempre a atualidade, enfim, que deveria nos guiar de maneira certeira, definindo não apenas o que pensar mas também como pensar.

Com essa formulação seminal, Foucault procurou inscrever o discurso filosófico no horizonte de seu tempo, isto é, nas linhas de força e nos antagonismos que permeariam o espaço social em que existia. Esta seria a maneira de inscrever o futuro no presente, sob a forma da sua antecipação. Procurou assim afastar aquele de uma posição meramente contemplativa, de forma a transformá-lo numa arma de combate das questões maiores da contemporaneidade. Para isso, no entanto, necessário seria que a filosofia abandonasse o seu ranço academicista, pelo qual se restringia à pura exegese dos sistemas filosóficos do passado e à escrita de novos comentários para a composição da história da filosofia, para se engajar definitivamente nas problemáticas maiores indicadas pela atualidade.

Não foi por acaso que Foucault escolheu para seu comentário pontual, sobre a inscrição da filosofia na atualidade, um ensaio de Kant que pertence 
aos escritos sobre a filosofia da história, em vez de comentar e empreender a exegese da Crítica da razão pura (Kant, 1974) da Crítica da razão prática (Kant, 1993) e da Crítica do juízo (Kant, 1995), como costuma acontecer com os historiadores da filosofia e os especialistas em Kant. Foucault teria assim se deslocado dos textos no qual a filosofia kantiana se articula e se fundamenta de forma sistemática, para se voltar para a periferia da produção de Kant, procurando retirar daquilo que seria fragmentar e inconcluso seu traço de atualidade.

A escolha de Foucault revela, pois, de maneira condensada e estratégica, sua ruptura radical com uma certa concepção de filosofia, que criticou desde o início de seu percurso teórico. Voltar-se para a indagação do estatuto da loucura, da medicina, da clínica, da punição, da literatura e da sexualidade, para encontrar nessas problemáticas, supostamente bastardas para a filosofia, a matéria-prima de seu projeto teórico, seria, enfim, assumir em ato e no gesto de produção a sua ruptura radical com uma certa concepção da filosofia.

Por isso mesmo, a disciplina cuja cátedra lhe foi conferida no Collège de France se intitulava precisamente "História dos sistemas de pensamento". Enunciava que os ditos sistemas de pensamento tinham uma história, sendo então uma produção dessa. Indicaremos adiante a crítica de Foucault à idéia de história, assim como sua proposição de realizar criticamente uma arqueologia do saber e uma genealogia do poder das suas problemáticas de pesquisa, que não se configuravam como da ordem da história. Por ora cabe apenas destacar o investimento teórico de Foucault em interrogar a constituição das categorias e dos conceitos no campo desses sistemas de pensamento, nas suas inscrições precisas nos contextos históricos e sociais de sua produção, tendo sempre na alça de mira o campo de forças presentes na atualidade. Seria este o projeto teórico de Foucault, que se materializava também na mestria institucional que empreendia regularmente.

Tudo isso implicava também sua assunção da problemática da finitude como marca e valor fundamental da filosofia na modernidade (Foucault, 1966). Não foi por acaso também que Foucault colocou a finitude como traço constitutivo da modernidade filosófica, sendo justamente Kant o pensador que teria enunciado tal imperativo na sua crítica sistemática da metafísica. Com efeito, em As palavras e as coisas, no capítulo em que delineia precisamente as condições de possibilidade de pensar nas novas relações então tecidas entre as palavras e as coisas, Foucault inscreve Kant naquilo que seria o originário da modernidade filosófica (Foucault, 1966), 
anunciando justamente a problemática da finitude. Estaríamos aqui, enfim, na inauguração da modernidade.

O reconhecimento da finitude como valor crucial do discurso filosófico na modernidade implica a crítica sistemática de qualquer pretensão de absoluto atribuída aos conceitos e enunciados da filosofia. A contrapartida disso seria o apelo recorrente à pontualidade e aos contextos nos quais aqueles se forjariam sempre. Com isso, o relativismo como critério de verdade se impõe, vinculado às variações impostas pela historicidade. Ao lado disso, a importância da atualidade para o pensamento de Foucault se evidencia aqui de outra maneira, articulando-se a essa exigência do relativismo.

Isso não quer dizer, em contrapartida, que os sistemas de pensamento não se cristalizem e se precipitem como tradição, passando a obcecar os pesquisadores. Porém, isso implica pensar como a tradição se forja e se constitui pela reprodução dos sistemas pelos comentadores, impondo-se como uma problemática fundamental para a indagação filosófica. Daí a investigação de Foucault se ter voltado justamente para o estudo da "História dos sistemas de pensamento", na qual se relativizava o horizonte dos enunciados e dos conceitos teóricos, numa articulação permanente com a atualidade.

Pode-se depreender disso tudo que é a idéia de verdade enquanto tal que estaria em questão no projeto teórico de Foucault.

\section{Jogos de Verdade}

A idéia de verdade seria colocada em suspenso, enquanto pretensão maior do discurso filosófico. Porque aquilo a que se atribuía valor de verdade numa dada tradição não estaria inscrito num registro de neutralidade, mas estaria sujeito também aos enfrentamentos de posições e aos jogos de força que perpassam o espaço social como um todo, como Nietzsche teria ensinado a Foucault numa das máximas de sua filosofia (Nietzsche, 1987). Nada escaparia ao horizonte dos confrontos (Foucault, "Les technologies de soimême", 1994). Por isso mesmo, seria preciso examinar as condições concretas de possibilidade de produção da verdade, inscrevendo-a na tessitura do espaço social e da história, para que se pudesse surpreender em estado nascente os processos de produção do verdadeiro e as modalidades de efetivação de sua legitimidade.

Nesta perspectiva Foucault formulou, ainda no final de seu percurso teórico, outro conceito seminal que lança bastante luz sobre o seu discurso. De maneira bastante ousada, enunciou que a verdade se inscreveria em 
jogos de verdade (Foucault, "Les technologies de soi-même", 1994). Assim, a verdade não tombaria do Cosmos, das idéias acima de qualquer suspeita, à Terra, mas das relações entre os homens, inserindo-se agora em jogos que regulariam o modo de produção de seus enunciados e as regras de produção de sua legitimidade.

Como formulou Foucault esse conceito? Evidentemente, o conceito de jogos de verdade foi forjado a partir do conceito de jogos de linguagem, formulado pelo segundo Wittgenstein, nas Investigações filosóficas (Wittgenstein, 1961). Como entender a alusão ao jogo? O que significa jogar nos registros da linguagem e da verdade? Seriam elas questões preliminares a serem bem compreendidas, antes de mais nada, para que se pudesse apreender o que estaria em pauta?

Parece-nos que, para ambos, afirmar que se trata sempre de um jogo, seja da linguagem seja da verdade, implica sublinhar a presença de uma regra que preside e que seria constitutiva do jogo enquanto tal. Porém, enunciar a existência de uma regra é indicar a existência de algo que é da ordem da invenção e do arbitrário, que seria constitutivo de toda e qualquer regra. Se esta é arbitrária, no entanto, não quer dizer que seja marcada pela arbitrariedade no sentido negativo da palavra, pois seria sempre compartilhada pelos possíveis jogadores, naquilo que ao mesmo tempo autoriza e proíbe.

A regra seria sempre compartilhada, sendo constituída pela convenção e pelo uso, ambos estabelecidos pelos homens no espaço social. A regra seria então uma produção social, que fundaria igualmente tanto os jogos de linguagem quanto os de verdade, inserindo-se no registro do artifício e não da natureza. Para Foucault e para Wittgenstein, enfim, a categoria de jogo remete tanto ao registro do social, que produziria e plasmaria a regra, quanto ao da história, que a reproduziria pelo seu uso recorrente.

Contudo, Foucault coloca ênfase na verdade e não mais apenas na linguagem, como em Wittgenstein, o que indica um deslocamento importante entre as duas categorias. Se a linguagem seria condição necessária para a produção da verdade como jogo, não seria, no entanto, condição suficiente. Com efeito, o que estaria presente nos jogos de linguagem de Wittgenstein remeteria certamente para a construção dos jogos de verdade de Foucault, mas para que estes se estabelecessem, necessária seria ainda a produção de certezas e crenças que se fundariam na ação de dispositivos de poder (Foucault, 1974), pelos quais a verdade se legitimaria e se inscreveria nos corpos dos indivíduos pela mediação de processos de subjetivação 
(Foucault, La volonté de savoir, 1976). O que distinguiria, portanto, a formulação teórica de Foucault daquela de Wittgenstein é a indicação precisa de que seria o poder o nexo crucial para a constituição dos jogos de verdade, pelo remanejamento que faria sempre do registro da linguagem, pelas relações de força que perpassariam o espaço social. Entre linguagem e verdade, enfim, o poder incidiria nos corpos das individualidades pela mediação de dispositivos.

Assim, se a verdade sempre se produziria e se reproduziria no campo dos jogos de verdade, não existindo naquela nada que pudesse ser da ordem do intangível e do absoluto, escrita que estaria insistentemente em relações de força reguladas pela microfísica do poder (Foucault, Microfísica do poder, 1976), isso implica, evidentemente, a possibilidade sempre colocada para se transformar as economias presentes nos jogos de verdade. Caberia ao teórico, neste contexto e perspectiva, o trabalho de incidir nesses jogos, pela leitura crítica e insistente de suas modalidades de formação, de cristalização e de enraizamento nas individualidades, para que possa enunciar outros jogos de verdade.

A finitude que marcaria e inauguraria a modernidade filosófica, como indicado acima, se articularia com o que existiria de móvel, tangível e relativo na constituição dos jogos de verdade. Por este viés o discurso filosófico se inscreveria necessariamente no mundo, marcado pelos fluxos e refluxos estabelecidos pelas relações de força inscritas no espaço social.

Pela consideração efetiva disso tudo se pode apreender a posição engajada da filosofia para Foucault e de como esse engajamento radical se inscreve de maneira orgânica no corpo de seu discurso. Isto é, seu compromisso visceral com o real de seu tempo, concebido em nível francês ou internacional. Existiria aqui uma leitura radical de que o real, na modernidade, constituiria o entrechoque permanente de forças em confronto, sendo as produções do saber um dentre outros ingredientes e vetores constitutivos das relações de força que compõem o cenário do espaço social onde circulamos.

Daí decorre o aforismo fundamental que condensa o discurso filosófico de Foucault, segundo o qual existiria uma relação de fundação entre saber e poder. Entre estes, a relação seria permanente e insistente. Não resta qualquer dúvida de que estamos aqui, com esse aforismo, no centro de seu pensamento teórico. 


\section{Saber e Poder}

É preciso considerar, no entanto, a modalidade de relação que se estabelece entre saber e poder. Não se trataria nem de uma utilização do saber que o poder faria para se legitimar enquanto tal, nem tampouco de um uso oportunista do poder realizado pelos agentes do saber. Isso não quer dizer que tais possibilidades não existam e ocorram de fato no espaço social. Porém, não é bem a isso que Foucault quer se referir quando alude às relações entre saber e poder de maneira mais fundamental. É para isso que temos que nos inclinar para não considerarmos essa tese na sua trivialidade cotidiana.

Nesta perspectiva, o que estaria em causa seria algo de ordem circular entre saber e poder, para se contrapor a uma concepção linear geralmente aceita dessas relações, pela qual o saber seria sempre determinado pelo poder, tendo pequena ou mesmo nenhuma ação fundamental sobre ele. Para Foucault existiria uma implicação recíproca entre saber e poder, enunciada numa mutualidade de relações entre esses pólos. Com isso, o círculo tende a assumir a forma de uma espiral, que como metáfora condensa melhor não apenas as relações mútuas entre saber e poder, como também indica como a mútua implicação acaba por criar um cenário no qual os oponentes se situam num desequilíbrio permanente e em posições espaciais diferentes. Os lugares seriam sempre móveis, jamais fixos, sempre marcados estrategicamente pela mutualidade imprevisível nos seus efeitos, nas relações que se estabelecem entre saber e poder.

Em decorrência disso, Foucault empreende a crítica da concepção de poder presente no marxismo, seja porque neste se enunciam de maneira linear e determinista as relações entre saber e poder, seja porque se formulam também numa atribuição de subalternidade do saber ao poder. Em ambos os registros, diversos mas complementares, o saber, enquanto positividade do poder, se silenciava no pensamento marxista.

Assim, num primeiro registro deste pensamento, o saber se inscreveria sempre no nível das superestruturas do campo social, sendo determinado, em última instância, pela infra-estrutura econômica de uma dada formação social. Nesta, certamente, o saber seria um simples efeito linear e mecânico daquilo que se passaria no confronto entre as forças produtivas e as relações de produção. A especificidade do saber se perderia então, sendo este silenciado na sua positividade.

Em contrapartida, o discurso marxista procurou elaborar outra formula- 
ção sobre o saber, concebendo sua inscrição no campo das formações ideológicas. Trata-se de uma proposição bem mais refinada que a anterior, mas que, mesmo assim, coloca o saber numa posição de subalternidade ao poder. Nesta versão, o saber se inscreveria sempre nos aparelhos ideológicos do Estado, que exerceria sua dominação pelo viés desses aparelhos. Tanto em Althusser (1980) quanto em Gramsci (1968), podemos encontrar tal formulação.

É claro que nessa outra formulação o saber se inscreve no registro do político, fazendo parte do seu campo, estando aqui a virtude dessa concepção em relação à anterior. Pode-se compreender, no entanto, que os ditos aparelhos ideológicos estariam subsumidos à soberania do Estado, que exerceria o poder em última instância. Por isso mesmo, enfim, o saber como parte integrante dos aparelhos ideológicos do Estado teria uma evidente subalternidade face a ele.

Depreende-se que evocar rigorosamente a categoria de poder, em Foucault, implica trazer novamente para a cena do social a dimensão do político. O político enquanto tal teria sido esquecido, por mais paradoxal que possa parecer inicialmente na referência crítica ao marxismo. Porém, não é apenas isso. Existe, ainda, uma concepção do político como marcado por relações de força entre os oponentes. As relações seriam sempre reguladas por táticas e estratégias, que visariam a produzir o efeito de assujeitamento e de quebra da resistência do adversário. Por esse viés o processo de dominação se faria, quebrando resistências para assujeitar os oponentes num contexto marcado sempre por relações de força.

Porém, considerar o que Foucault pretende efetivamente dizer com sua tese implica destacar a especificidade do poder na modernidade, em que outras relações se estabelecem entre o poder e o saber. É nesse contexto que a formulação foucaultiana se desdobra, tomando corpo e forma, evidenciando sua riqueza teórica. Apenas na modernidade teria se constituído o poder disciplinar, que se exerceria sempre através dos saberes, criando um amálgama novo entre saber e poder que inexistia na Idade Clássica. $\mathrm{Na}$ leitura do dito poder disciplinar, a formulação de Foucault ganha peso conceitual e fôlego teórico (Foucault, 1974). Estaria justamente aqui sua novidade teórica.

Assim, em função disso Foucault realizou a crítica da tradição marxista acima referida. Porém, a crítica não se restringe a essa tradição apenas, mas se estende também à filosofia política. Com efeito, o que está em questão aqui é o deslocamento que teria se operado no poder, na 
modernidade, que teria migrado de seu centro, isto é, o Estado, para aquilo que se processaria na sua periferia, que seria o campo social enquanto tal. A inversão de leitura face ao marxismo e a filosofia política se situa exatamente neste ponto preciso. A problemática do poder se teceria no espaço social, este sendo sempre atravessado por diferenciais de força entre os corpos, que estabeleceriam entre si relações de dominação e de assujeitamento.

Deve-se sublinhar não apenas a palavra corpo mas também o seu corolário - isto é, o espaço -, na medida em que o poder teria sempre no corpo o seu território de ação e o seu ponto de incidência, assim como se enraizaria no social, concebido como espacialidade e como teatro de ação. Vale dizer, a dominação e o assujeitamento incidiriam sempre nos corpos das individualidades, que precisariam ser domesticados e disciplinados, enquanto que a resistência ao poder viria sempre do registro corporal. Além disso, seria no espaço que os corpos se dispõem e se distribuem nas suas diferenças de força.

Por isso mesmo, o poder disciplinar se realizaria sempre pela ação de micropoderes que permeariam a totalidade do espaço social (Foucault, 1974). Eles se ordenariam como uma rede difusa e penetrante, que se capitalizaria no campo do social. Esse deslocamento do poder do centro para a periferia do social se materializaria já aqui, onde, no tecido das relações, se plasmariam os efeitos do poder propriamente ditos. Os micropoderes seriam dispositivos através dos quais as disciplinas se materializariam, nos quais se formalizariam as relações íntimas entre saber e poder.

Pela mediação insistente e produtiva de dispositivos inscritos numa rede capilar de micropoderes, o poder disciplinar empreenderia a normalização do espaço social (Foucault, 1974). O processo de produção e de reprodução de normas, assim como o seu permanente remanejamento com vistas à dominação e ao assujeitamento dos corpos, seria a finalidade fundamental do poder disciplinar. Não havia dúvida: seria sempre o corpo que deveria ser normalizado no campo do poder disciplinar. Seu alvo é sempre o corpo, que seria visado pelas diferentes estratégias e táticas da normalização.

Não foi certamente por um acaso que Foucault se interessou pela medicina como saber e poder, nos seus registros individual e coletivo, na modernidade. Isso porque a medicalização do espaço social na modernidade se realizou pela clínica e pela medicina social (Foucault, Naissance de la clinique, 1963), constituindo, ao mesmo tempo, um novo lugar atribuído para a medicina na aurora do mundo moderno. Através dela o espaço social foi 
esquadrinhado meticulosamente, polarizado entre o normal e o anormal (idem) de maneira a caucionar o processo de normalização dos corpos. A clínica constituiu o primeiro dispositivo de exame, que se estendeu em seguida para as demais ciências humanas (idem) estando no fundamento antropológico do poder disciplinar propriamente dito.

Partindo do modelo constituído pela medicina, os demais dispositivos disciplinares foram constituídos, e neles as diferentes ciências humanas se constituíram e se inscreveram. Isso porque a medicina teria constituído o primeiro saber sobre o particular na tradição ocidental, rompendo definitivamente com a concepção aristotélica de que existiria apenas saber sobre o universal (Foucault, Naissance de la clinique, 1963). Foi sempre na ênfase sobre o particular que as diferentes ciências humanas se constituíram e se inscreveram como dispositivos no campo do poder disciplinar, na medida em que este exerce o processo de normalização sobre as particularidades e não mais sobre o universal (idem). Estaria aqui a originalidade do poder disciplinar: ele visaria sempre ao particular, situado no registro individual ou coletivo. Seria sempre o particular o alvo do processo de normalização. Aqui, enfim, o poder disciplinar se exerce efetivamente.

A pesquisa de Foucault se desdobrou na sua preocupação teórica com o biopoder, que teria constituído a bio-história na modernidade. Na política dos Estados modernos, a preocupação com a qualidade de vida das populações teve no biopoder seus dispositivos fundamentais, ao considerar o campo da sexualidade e da reprodução como seus alvos estratégicos. A riqueza das nações passou a ser concebida e calculada meticulosamente, tendo na qualidade de vida da população sua matéria-prima fundamental (Foucault, La volonté de savoir, 1976).

Em tudo isso, evidentemente, as relações entre poder e saber seriam íntimas e fundamentais, plasmando-se no poder disciplinar, que se materializaria sempre em dispositivos e micropoderes inscritos numa rede capilar difusa no espaço social. Tudo visaria, enfim, à normalização dos corpos, encarados sempre como alvos particularizados.

Em decorrência desta leitura sobre a analítica do poder na modernidade, Foucault realizou a crítica da tradição da filosofia política e do marxismo, que se centravam no lugar estratégico atribuído ao Estado na política moderna. Para ele, essa modalidade de leitura teria uma marca eminentemente pré-moderna, fundando-se naquilo que denominou de poder soberano (Foucault, 1974). Enquanto tal, o Estado-Rei era sempre resplandescente e luminoso, silenciando as particularidades de seus súditos com a força de seus 
exércitos e a delegação divina de seu poder absoluto. A modernidade estaria na contracorrente disso, deslocando agora o poder para as particularidades inscritas na periferia, que como individualidades seriam produzidas e normalizadas pelos dispositivos dos micropoderes, em cujas redes o saber se capilarizava (idem).

\section{Problemáticas}

Pode-se retomar aqui, por outro viés, a problemática, já aludida, dos jogos de verdade. Com efeito, estes seriam plasmados no campo das disciplinas, produzidos sempre pelos dispositivos nelas inscritos, constituindo diversas modalidades de assujeitamento. Por essas trilhas tortuosas, portanto, as subjetividades seriam forjadas pelos efeitos dos jogos de verdade.

Existe uma concatenação conceitual sempre precisa e rigorosa, pela qual os pólos do saber e do poder se articulam de maneira orgânica, gestando o real dos corpos das individualidades, pelos processos de normalização do social. Uma reflexão renovada da política se empreende aqui, na qual a posição estratégica do saber se revela como fundamental. Quanto a isso, Foucault produziu uma leitura bastante original, na qual o saber ocuparia lugar crucial no funcionamento do poder disciplinar. Por isso mesmo, podese dizer de maneira insistente que não apenas o saber é uma modalidade de poder e não apenas seria utilizado por esse, como também não existiria poder sem as produções do saber.

Podemos retomar o ponto de partida desta incursão - qual seja, a preocupação constante de Foucault com a atualidade, maneira de interpretar a indagação de Kant sobre o que seria o Iluminismo. Não obstante ter ocupado as posições institucionais mais cobiçadas pelos intelectuais franceses, Foucault nunca foi um acadêmico no sentido tradicional do termo, como decorrência de sua concepção engajada da filosofia.

Tal concepção se inscreve na coluna vertebral de seu discurso teórico, pelos conceitos que enunciou: jogos de verdade, poder, saber, disciplina e formas de subjetivação. Assim, mesmo que suas formulações teóricas tenham acabado por se transformar em moda intelectual, no mundo acadêmico internacional, foram sempre forjadas em ressonância com o que se passava no espaço social de seu tempo, procurando incidir na lógica de suas relações de força. Pretendia sempre redirecionar o campo dessas relações na atualidade, incidindo nos jogos de verdade que se inscreviam nos dispositivos de poder. 
Nesta perspectiva, não foram um acaso as problemáticas teóricas que Foucault escolheu para a realização de suas pesquisas. Foi sempre a lógica presente nos jogos de verdade, no campo da atualidade, que o conduziu nas suas escolhas. Estas tinham sempre um caráter estratégico, que delineava suas opções táticas. Com efeito, iniciou seu percurso por uma interpelação radical do estatuto de loucura no Ocidente e concluiu com a indagação do lugar da sexualidade no campo da ética, passando pela nova medicina na aurora da modernidade, pelas formas outras de saber, pela discursividade, pelo poder e pelas modalidades originais de punição na modernidade. Foucault se voltava sempre para as questões cruciais de seu contexto histórico, sublinhando as linhas de fratura delineadas pela articulação entre saber e poder.

Interpelar a posição estratégica ocupada pelo processo de psiquiatrização do Ocidente, assim como os lugares específicos da psiquiatria e da psicanálise, na modernidade, considerando as reformas em curso nos anos 60, implicava uma escolha estratégica fundamental para indicar a oposição fundamental entre razão e desrazão na nossa tradição (Foucault, Histoire de la folie à l'âge classique, 1971). Em seguida, ainda no contexto de renovação da medicina nos anos 60, Foucault precisou indicar as condições concretas de possibilidade para a emergência da clínica no final do século XVIII e sua construção ao longo do século XIX, indicando a novidade não apenas de um saber sobre o particular mas também de uma medicina do espaço social (Foucault, Naissance de la clinique, 1963).

Com isso, o dispositivo de normalização da medicina, polarizando e esquadrinhando o espaço social entre o normal e o patológico, possibilitou outro olhar sobre o corpo e a construção arqueológica das demais ciências humanas. Em As palavras e as coisas, delineou passo a passo as transformações ocorridas nos processos de produção de verdade, da Idade Clássica à modernidade, que se desdobraram na construção do homem como figura antropológica e na previsão ousada de seu desaparecimento próximo (Foucault, 1966).

Pela leitura da discursividade, numa concepção crítica do estruturalismo, procurou indicar como o engendramento da textualidade na sua articulação com o poder condensa formas de produção de verdade na construção de seus enunciados e nas regras de formação de arquivos (Foucault, L'ordre du discours, 1971).

Em Arqueologia do saber, procurou indicar o seu método de investigação, assim como inscreveu as diversas textualidades no seu campo de inda- 
gação (Foucault, 1969), evidenciando as suas diferenças em relação ao estruturalismo e à história.

A viragem para a genealogia começou a tomar corpo e forma na passagem dos anos 60 para os anos 70, articulando a arqueologia do saber no campo da genealogia do poder (Foucault, 1974). As formulações teóricas entre os registros do saber e poder ficaram cada vez mais precisas, recortadas de maneira mais rigorosa. Em Vigiar e punir, procurou forjar as diferenças entre poder soberano e poder disciplinar, passando a delinear as formas de ação dos dispositivos e da microfísica do poder. As modernas modalidades de punição, que teriam na prisão e no panóptico suas materializações ostensivas, se destacam como problemática maior, no contexto privilegiado de debates sobre o sistema penitenciário na França (idem).

A estética da existência se ordenou ao longo da pesquisa final sobre a História da sexualidade, na qual a inscrição ativa do sexual nos modernos sistemas disciplinares serviu de contraponto para a crítica e desconstrução das teorias da repressão, que dominavam o cenário intelectual de então, tendo na psicanálise sua referência fundamental. A soberania da lei da interdição do incesto foi desconstruída em nome das disciplinas realizadas sobre o corpo sexuado, que encontrou nas figuras da mulher histérica, do perverso e da criança os alvos para a medicalização do social. O biopoder teria aqui se ordenado e se desdobrado nas suas táticas para a produção da bio-história, visando à produção da população qualificada como a fonte maior de riqueza das nações, num contexto onde as biotecnologias já apareciam no cenário internacional (Foucault, La volonté de savoir, 1976).

Tudo isso nos indica como a imersão na atualidade e na finitude, como marcas da filosofia na modernidade, conduziram Foucault para a escolha de seus temas no contexto histórico, político e social, para transformá-los em problemáticas complexas para a interpelação arqueológica e genealógica. Visava com isso a delinear a história dos sistemas de pensamento que constituíram tais problemáticas nas suas articulações com os dispositivos de poder. Os jogos de verdade eram vistos como alvos, nas suas descontinuidades e continuidades, nas suas rupturas e permanências. Tudo isso indicaria sempre a historicidade e o relativismo das categorias e critérios de verdade que se constituíram, evidenciados que eram pela arqueologia do saber e pela genealogia do poder.

É para a leitura dos conceitos de continuidade e de descontinuidade que vamos nos voltar agora, para marcar seu lugar no discurso teórico de Foucault, assim como a constituição da categoria de saber. 


\section{Descontinuidades e Saberes}

Assim, na constituição do pensamento de Foucault não se pode deixar de considerar os efeitos paradoxais, que foram produzidos pela moderna tradição epistemológica francesa que, sobretudo com Bachelard e Canguilhem, procurou romper radicalmente com a perspectiva de uma concepção positivista da ciência. No campo daquela moderna epistemologia, a posição de Foucault foi de marcante ruptura. Porém, indicar seus signos é fundamental, para bem delinear seu discurso teórico.

$\mathrm{Na}$ moderna epistemologia francesa, a preocupação com a produção do conceito estava no seu fundamento, de maneira que os fatos e acontecimentos produzidos pelo discurso científico teriam sempre uma relação de fundação com os conceitos que lhes enunciavam. Desta maneira, o objeto dos diferentes discursos científicos seria sempre produzido por conceitos que o forjariam, constituindo-se, pois, como objeto teórico propriamente dito. Isto é, seriam produções do pensamento e não simples indicações de fenômenos inscritas no registro da percepção.

Nesta perspectiva, seria estabelecida uma ruptura radical entre os discursos da ciência e da pré-ciência, que se evidenciaria de maneira eloqüente na construção de um dado objeto teórico. A categoria de corte epistemológico, formulada por Bachelard, procurou fundar essa leitura do discurso da ciência na sua ruptura com o senso-comum (Bachelard, 1975).

Com isso se pode forjar outra interpretação da história das ciências, na qual esta não seria mais a simples narrativa dos eventos científicos, das academias e dos personagens que teriam participado da constituição de um dado campo científico. Caberia agora, nesse outro contexto, indicar como se produziu um dado campo científico, isto é, os momentos cruciais nos quais foram forjados seu objeto teórico e seu campo conceitual, assim como os cortes epistemológicos que teve que realizar para que isso fosse possível (Canguilhem, 1968). Para empreender isso, necessário seria indicar os impasses presentes no imaginário do senso-comum para a emergência de um novo campo científico. A isso Bachelard denominou de obstáculo epistemológico (Bachelard, 1975). Nesta perspectiva, existiria uma articulação íntima entre a filosofia e a história das ciências, na medida em que a primeira enunciaria os critérios para a segunda, considerando sempre a constituição de um dado campo conceitual e do objeto teórico correlato.

O mesmo discurso teórico foi retomado por Althusser numa perspectiva marxista, quando considerou o imaginário do senso-comum como delineado 
pela ideologia, de maneira que a construção de uma certa discursividade científica se faria sempre pela desconstrução de um certo campo da ideologia (Althusser, Pour Marx, 1965; Althusser, Lure le Capital, 1965). A história das ciências seria então o desmantelamento insistente do campo das ideologias, e a produção progressiva da verdade pela ciência se faria pela desconstrução das ideologias e superstições presentes no imaginário popular.

De qualquer forma, considerando-se a passagem entre os registros da ciência e do senso-comum, ou localizando-se aquela entre os da ideologia e da ciência, o advento do discurso científico indica uma concepção descontínua da filosofia e da história das ciências. A verdade seria sempre forjada contra o registro da não-verdade que lhe faz resistência e a isso se opõe, indicando o progresso da verdade. Estaria aqui a novidade dessa concepção teórica face ao Positivismo, na medida em que estaríamos sempre numa versão contínua entre aqueles registros.

Qual a implicação disso? Enunciar a descontinuidade no campo da verdade, inscrevendo-a na filosofia e na história das ciências, implica formular ao mesmo tempo a descontinuidade da consciência. Isso evidenciaria a historicidade das ciências, que passaria a exigir uma epistemologia regional e não mais universal, quanto a da própria idéia de verdade que seria daquela correlata, já que o conceito constitutivo de um dado objeto teórico se plasmava como verdade.

Foucault se formou no campo dessa tradição teórica, tendo em Canguilhem um de seus mestres. Empreendeu, porém, a crítica dessa tradição, na sua arqueologia do saber e na sua genealogia do poder, ao misturar as cartas presentes nos jogos de verdade sobre a continuidade e a descontinuidade. O que estava em pauta era a própria categoria de verdade na sua oposição radical a de não-verdade, pela qual se contrapunham os registros da ciência e do senso-comum, isto é, os universos da ciência e da ideologia.

Assim, Foucault criticou a ruptura existente entre a ciência e o sensocomum, afirmando as continuidades existentes num dado campo histórico, entre ambas. Foi a sua maneira de dizer que não existia qualquer progressão em direção à verdade outorgada pelas ciências, que se desprenderam das obscuridades presentes nas ideologias. Existiriam continuidades entre tais registros, num dado contexto histórico, organizados que seriam pelas mesmas categorias de pensamento. Em contrapartida, existiriam rupturas entre diferentes campos históricos, na medida em que se transformariam as ditas categorias de pensamento. Porém, tais mudanças incidiriam igualmente nos registros diversos das ideologias e das ciências. 
Foucault denominou de episteme as categorias que ordenariam igualmente os campos do senso-comum e da ciência de um dado horizonte histórico. Seriam as epistemes que se transformariam na passagem de um certo campo histórico para outro, mudando radicalmente as maneiras de conceber o mundo e as coisas. Destacando a categoria de episteme, Foucault procurou superar a oposição existente entre ciência e ideologia, enunciando a categoria de saber (Foucault, 1966 e 1969). Para ele, uma indagação sobre o saber sempre assumiria a forma decisiva de uma arqueologia do saber e de uma genealogia do poder.

Porém, da mesma maneira que o aforismo fundamental enunciado por Foucault sobre a relação de fundação entre saber e poder procurava delinear a originalidade assumida pelo poder na modernidade como poder disciplinar, a preocupação maior de Foucault era a constituição de saber na modernidade (Foucault, 1966), na sua articulação íntima com a problemática do poder que realizou posteriormente (Foucault, 1974). Com efeito, do Renascimento à modernidade, passando pela Idade Clássica, Foucault procurou delinear as diferentes epistemes que foram então enunciadas para a produção dos jogos de verdade. Assim, da episteme centrada na representação para a que se inscreveu no tempo e na história (Foucault, 1966), não estaríamos mais diante de uma progressão infalível do espírito em direção à verdade, mas de diferentes modalidades de conceber o sujeito, o mundo, as coisas e os objetos. Isto é, estaríamos lançados decididamente em diversos jogos de verdade, sem qualquer hierarquia valorativa quanto à veracidade entre eles.

Remanejando então a cartografia epistemológica entre continuidade e descontinuidade - mantendo a primeira num registro e a segunda num outro, para enunciar a idéia de verdade no campo imantado de um jogo -, Foucault inscreveu no discurso filosófico aquilo que se evidenciara já com o recente discurso antropológico, que enunciava o relativismo presente na leitura das diferentes tradições culturais, assim como o que então se empreendia no campo da história. Com efeito, seja pela concepção de uma história de longa duração (Le Goff, 1989), seja pela história de novos objetos que se afastaria da tradicional história política das nações (Le Goff e Nora, 1970; Le Goff e Nora, "Nouveaux problèmes", 1974; Le Goff e Nora, "Nouveaux approches", 1974), Foucault passou a conceber as categorias do pensamento como relativas num tempo de longa duração, sujeitas a descontinuidades, mas com continuidades num certo contexto histórico, além de introduzir problemáticas então inéditas para a investigação filosófica como novos ob- 
jetos. Pôde empreender, enfim, a interpelação crítica da razão, da medicalização, das discursividades, dos saberes, da punição e da sexualidade, de forma sempre brilhante e colocando seu insistente alvo teórico na constituição dos jogos de verdade.

O que se pode depreender disso tudo é que Foucault não tem a pretensão de ser um historiador. Pelo contrário, para ele a História seria o último reduto do continuísmo (Foucault, 1967). Seu projeto se constituiu justamente contra isso, apoiando-se sobre a descontinuidade na constituição da verdade através das epistemes e regulada pelos dispositivos de poder. Para empreender isso, no entanto, se inscreveu na tradição da genealogia inaugurada por Nietzsche (Foucault, "Nietzsche, la génealogie, l'histoire", 1971) e criticou a concepção continuísta da História. Interpelou sempre de maneira descontínua, portanto, a construção de uma dada problemática da atualidade, articulando a arqueologia do saber com a genealogia do poder do Renascimento à modernidade, passando pela Idade Clássica.

Pode-se reconhecer que o projeto filosófico de Foucault se constituiu pela indagação crítica dos jogos de verdade estabelecidos, propondo, ao mesmo tempo, outros jogos de verdade sobre as mesmas problemáticas. Com efeito, da desrazão à sexualidade, passando pela medicina, pela discursividade e pelas modalidades de punição, a filosofia de Foucault é uma desconstrução insistente dos jogos de verdade, o que indica sua inscrição nos dispositivos de poder.

Como não poderia deixar de ser, o discurso de Foucault sobre a descontinuidade da verdade - esta inscrita sempre em jogos de verdade e nos dispositivos de poder, assim como a descontinuidade presente nos sistemas de pensamento - se desdobrou na interpelação da categoria de sujeito. Justamente aqui se plasmariam, em última instância, as categorias de verdade e de continuidade.

Pode-se dizer que esta interpelação permeia a totalidade do percurso teórico de Foucault, mesmo quando isso não se enuncia sempre claramente, de maneira frontal, como na sua pesquisa final sobre a estética da existência. Enquanto problemática, no entanto, está sempre lá presente, nas entrelinhas das demais problemáticas que atravessou criticamente - isto é, como virtualidade insistentemente instigadora que se ramificou por todos os territórios de sua pesquisa filosófica. 


\section{Sujeito e Formas de Subjetivação}

É claro que não existe nada de surpreendente no que foi dito acima. A travessia do discurso filosófico de Foucault nos evidencia isso sem dificuldade, indicando os impasses da categoria de sujeito.

A construção da arqueologia da razão, tendo na desrazão o seu contraponto e negativo, iniciada na Idade Clássica e se desdobrando na modernidade, com o advento da psiquiatria e da psicanálise, já mostrava isso de maneira certeira e patente (Foucault, Histoire de la folie à l'âge classique, 1971). Foi o próprio campo da problemática da verdade, formalizado positivamente nas categorias de sujeito e de razão, tendo na loucura e no delírio a sua negatividade, que foi colocada em questão de maneira frontal em $A$ história da loucura na Idade Clássica. Com efeito, entre a concepção trágica e a concepção crítica da loucura, nas quais esta se deslocou decisivamente do registro da verdade para o da não-verdade, aquela acabou por ser lançada na periferia pela tradição do Ocidente e desta excluída, como sendo o Outro da razão e do sujeito. De Descartes a Hegel, passando por Kant, o discurso filosófico se fundou como tradição, tendo no sujeito o seu fundamento e na loucura como desrazão o território sagrado de sua impossibilidade. Entre arte e ciência, deslocando-se do registro da verdade para o da não-verdade, de maneira infalível e sendo medicalizada pela psiquiatria, a loucura seria a formalização da impossibilidade de ser sujeito e razão (Foucault, 1966).

No entanto, foi para indicar que o sujeito e os seus correlatos - isto é, as categorias de verdade e de razão seriam sempre jogos de verdade - que Foucault constituiu seu projeto filosófico e enunciou a existência de outros jogos de verdade. Para isso, contudo, necessário seria radicalizar a idéia de descontinuidade no registro do sujeito, pela assunção radical da descontinuidade efetiva da consciência. Se essa fosse descontínua no seu ser, a loucura não poderia mais ser considerada como desrazão e não-verdade, como se estabeleceu, aliás, na tradição do jogo de verdade fundado na razão.

Em decorrência disso, Foucault pode acolher no seu projeto teórico o conceito de descentramento do sujeito - isto é, de que a subjetividade não se centraria mais nos registros do eu e da consciência. Dizer que aquela não teria centro seria afirmar ao mesmo tempo que não teria mais fundamento, de maneira a apagar as fronteiras entre sujeito e não-sujeito (Foucault, 1966). Repete-se aqui, pois, o mesmo gesto empreendido na desconstrução do jogo de verdade sobre a razão.

A aproximação estratégica de Foucault com a psicanálise se processa 
pela desconstrução da categoria de sujeito como fundamento. A psicanálise ofereceu para ele a possibilidade de conceber a subjetividade como descentramento (Foucault, 1967). Porém, quando a psicanálise se travestia com os filosofemas do discurso filosófico do sujeito, como em algumas das formulações de Lacan, Foucault se transformava num crítico impiedoso dela (Birman, 2001).

Se a psicanálise ocupou uma posição estratégica no discurso de Foucault, isto se deveu, sem dúvida, ao lugar crítico ocupado pelo sujeito no seu interior. Enquanto representava o sujeito sem fundamento e descentrado, a psicanálise se inscrevia positivamente no projeto teórico de Foucault. Caso contrário, quando reconstituiu o sujeito como fundamento e verdade, aquela retomava a tradição que Foucault criticava sistematicamente.

Por isso mesmo, centrou-se no discurso teórico de Lacan como alvo para a sua crítica, considerando-o ora como um aliado, ora como um inimigo. Em "Nietzsche, Freud, Marx" (1967) e em As palavras e as coisas (1966), Foucault apostava que, pelo registro do inconsciente, a idéia de descentramento tinha sido entreaberta pela psicanálise. Porém, ao conjugar a arqueologia do saber à genealogia do poder, a interpretação positiva do projeto psicanalítico foi balançada de maneira radical por Foucault.

Com efeito, os conceitos psicanalíticos de Édipo, de lei simbólica e de interdição do incesto passaram pelo crivo crítico de Foucault (Foucault, $L a$ volonté de savoir, 1976) alçadas à condição de fundamento do sujeito e da sexualidade. Todos remetiam, pela mediação do conceito de lei simbólica, para a concepção soberana do poder - isto é, para uma leitura pré-moderna deste. O que estaria agora em pauta seria então a inscrição da psicanálise no campo do poder disciplinar.

Assim, para Foucault, a sexualidade não seria aquilo que teria que ser libertado, como se formulou na hipótese repressiva e que teve na psicanálise um de seus alicerces teóricos. Nunca se falou tanto dela como na modernidade, colocando a sexualidade nos jardins dos discursos, bem antes da emergência histórica da psicanálise, com Freud, no final do século XIX. Pelo discurso inflacionado sobre a sexualidade, esta foi constitutiva do imaginário da subjetividade moderna, sendo por este viés que a concepção de que a sexualidade seria a verdade do sujeito pode ser enunciada pela psicanálise. A psicanálise constituiu um jogo de verdade no qual a sexualidade seria o fundamento do sujeito do inconsciente $\mathrm{e}$ a sua verdade. A psicanálise seria, portanto, mais um capítulo, importante sem dúvida, para inscrever a sexualidade como fundamento do sujeito (Foucault, $L a$ volonté de savoir, 1976). 
Pelo projeto filosófico da estética da existência, Foucault procurou conceber outra leitura sobre a subjetividade, na qual esta seria agora pensada sem qualquer referência à categoria de sujeito como fundamento. Pela retomada das tradições grega (Foucault, L'usage des plaisirs, 1984) e romana (Foucault, Le souci de soi, 1984), Foucault buscava as indicações seguras para outra concepção de subjetividade, na qual a sexualidade se inscrevesse num outro ethos e em outros jogos de verdade. A idéia de cuidado de si, como constitutiva da subjetividade na Antigüidade, se oporia radicalmente à de saber de si, cultuada pela tradição da filosofia do sujeito e pelo cristianismo (Birman, 2001). Da mesma maneira, a arte erótica, cultivada em outras tradições culturais, se oporia à idéia de ciência sexual, cultivada pela modernidade ocidental (Foucault, La volonté de savoir, 1976).

Com tudo isso, portanto, o que estaria sempre em pauta seria a crítica da categoria de sujeito como fundamento, procurando Foucault indicar que se tratava de um mero jogo de verdade, constituído pelo Ocidente numa inflexão decisiva de sua história. Para desconstruir esse jogo, necessário seria pressupor que o sujeito não seria mais fundamento mas produção, forjado sempre pelo pensamento do fora (Foucault, "La pensée du dehors", 1994). Enfim, seria preciso mostrar agora que o sujeito como fundamento e saber de si não passaria de uma forma de subjetivação (Foucault, La volonté de savoir, 1976), dentre outras que seria possível para conceber a subjetividade.

\section{Referências Bibliográficas}

ALTHUSSER, L. Aparelhos ideológicos do Estado. In: ALTHUSSER, L. Posições-2. Rio de Janeiro: Graal, 1980. Lure le capital. Paris: Maspero, 1965.

ALTHUSSER, L. Pour Marx. Paris: Maspero, 1965.

BACHELARD, G. La formation de l'esprit scientifique. Paris: Vrin, 1975. BIRMAN, J. Entre cuidado e saber de si: Foucault e a psicanálise. Rio de Janeiro: Relume Dumará, 2001.

CANGUILHEM, G. Études d'histoire et de philosophie des sciences. Paris: Vrin, 1968.

FOUCAULT, M. Qu'est-ce les Lumières? In: FOUCAULT, M. Dits et Écrits. Paris: Gallimard, 1994. v. 4. 
La pensée du dehors. In: FOUCAULT, M. Dits et écrits. Paris: Gallimard, 1994. v.1.

Les technologies de soi-même. In: FOUCAULT, M. Dits et écrits. Paris: Gallimard, 1994. v.4.

Nietzsche, Freud, Marx. In: Nietzsche. Cahiers de Royaumont.

Paris, Minuit, 1967.

. Nietzsche, la génealogie, 1'histoire. In: HUMMAGE à Jean

Hyppolite. Paris: Presses Universitaires de France, 1971.

Dits et ecrits. Paris: Gallimard, 1994. v.1

Dits et ecrits. Paris: Gallimard, 1994. v.2

Dits et ecrits. Paris: Gallimard, 1994. v.3

Dits et ecrits. Paris: Gallimard, 1994. v.4

. Histoire de la folie à l'âge classique. Paris: Gallimard, 1971.

L'archéologie du savoir. Paris: Gallimard, 1969.

. L'Herméneutique du sujet. Paris: Gallimard , 2001.

. L'ordre du discours. Paris: Gallimard, 1971.

L'usage des plaisirs. Paris: Gallimard, 1984.

La volonté de savoir. Paris: Gallimard, 1976.

Le souci de soi. Paris: Gallimard, 1984.

Les anormaux. Paris: Gallimard , 1999.

Les mots et les choses. Paris, Gallimard, 1966.

Maladie mentale et psychologie. Paris: Presses Universitaires

de France, 1954.

. Microfísica do poder. Rio de Janeiro: Graal, 1976.

- Naissance de la clinique. Paris: Presses Universitaires de

France, 1963.

Raymond Russel. Paris: Gallimard, 1963.

Surveiller et punir. Paris: Gallimard, 1974.

GRAMSCI, A. Os intelectuais e a organização da cultura. Rio de Janeiro: Civilização Brasileira, 1968.

KANT, E. Critique de la faculté de juger. Paris: Vrin, 1995.

Critique de la raison pratique. Paris: Presses Universitaires

de France, 1993.

France, 1974.

Critique de la raison pure. Paris: Presses Universitaires de

LE GOFF, J. A história nova. São Paulo: Martins Fontes, 1989.

LE GOFF, J., NORA, P. Faire l'histoire: nouveaux approches. Paris:

Gallimard, 1974. 
Faire l'histoire: nouveaux objets. Paris: Gallimard, 1970.

Faire l'histoire: nouveaux problèmes. Paris: Gallimard, 1974.

NIETZSCHE, F. A genealogia da moral. São Paulo: Brasiliense, 1987.

WITTGENSTEIN, L. "Investigations philosophiques". In: WITTGENSTEIN, L. Tractatus logico-philosophicus suivi de Investigations e philosophiques. Paris: Gallimard, 1961.

\section{NOTAS}

1 Psicanalista, presidente do Espaço Brasileiro de Estudos Psicanalíticos. Professor titular do Instituto de Psicologia da UFRJ e professor adjunto do IMS/UERJ.

2 Ver Foucault (1954 e Histoire de la folie..., 1971).

3 Ver Foucault (Raymond Russel, 1963 e L'ordre du discours, 1971).

4 Ver Foucault (1966 e 1969).

5 Ver Foucault (La volonté de savoir, 1976; L'usage des plaisirs, 1984 e Le souci de soi, 1984).

6 Ver Foucault (1999 e 2001).

\section{ABSTRACT}

\section{Playing with the Truth}

This article proposes a reading of Foucault's thinking based on the "games of truth" category enunciated at the end of his theoretical trajectory. The attempt is made to establish similarities and differences between this category and that of language games, as stated by Wittgenstein in Philosophical Investigations. Foucault took this approach to conduct his critique of metaphysical tradition.

Keywords: Games of truth; language games; archeology; genealogy.

Recebido em: 30/09/2002.

Aprovado em: 12/11/2002. 